\title{
SATURATION OF THE MAGNETOSPHERE DURING SUPERSTORMS: NEW RESULTS FROM THE MAGNETOGRAM INVERSION TECHNIQUE
}

\author{
V.V. Mishin \\ Institute of Solar-Terrestrial Physics SB RAS, \\ Irkutsk,Russia,vladm@iszf.irk.ru
}

\author{
Yu.A. Karavaev \\ Institute of Solar-Terrestrial Physics SB RAS, \\ Irkutsk,Russia,ykar@iszf.irk.ru DOI: 10.12737/szf-33201704
}

\begin{abstract}
Using data on three superstorms, we study new features of the saturation of the polar cap area when the solar wind (SW) increases. The polar cap saturation is shown to occur when the SW dynamic pressure and southward vertical (IMF) component rise. The saturation is realized not only during the passage of interplanetary magnetic clouds, but also at significant enhancement of SW density when the SW thermal pressure is comparable with the pressure of the interplanetary magnetic field. We assume that under such conditions the saturation is caused not only by a decrease in the efficiency of reconnection at the dayside magnetopause, but mainly by finite magnetosphere compressibility - stopping the magnetopause compression due to a rapid earthward growth of the
\end{abstract}

geomagnetic field, i.e. the inner magnetospheric structure of the geomagnetic field. We have found signs of saturation depending on the northward IMF component. We assume that the IMF-dependent saturation exists for both signs of its vertical component due to an increase in the total pressure in the magnetosheath. Moreover, when penetrating into the magnetosphere, the southward IMF component reduces the geomagnetic field and thereby causes additional compression of the magnetopause and, accordingly, an increase in the saturation level of the polar cap area.

Keywords: magnetosphere, solar wind, polar cap, magnetic flux

\section{INTRODUCTION}

In the magnetosphere there are two families of field lines: closed field lines related to the internal magnetosphere and open lines related to the external magnetosphere (the region of the entry layer at the dayside boundary and tail lobes). The open field lines are projected onto the near-polar ionospheric region the polar cap. Through the polar cap along the open field lines, reconnected with the interplanetary magnetic field (IMF), a magnetic flux and electromagnetic energy flux - the Poynting flux $\mathbf{S}$, whose modulus we will denote by $\varepsilon$ ', following [ Mishin, 1990], propagate from the solar wind (SW) into the ionosphere. Magnetic energy accumulation during magnetospheric storms and substorms in geomagnetic tail lobes causes an increase in the lobes, polar cap area, and $\varepsilon^{\prime}$ fluxes transported through it. This is followed by explosive releases of the accumulated energy appearing, for example, as auroras, amplification of electric fields and currents in the polar ionosphere. The polar cap area and its associated transpolar potential $U_{\mathrm{PC}}$ with increasing $\mathrm{SW}$ grow linearly with an increase in the southward IMF component $B_{\mathrm{S}}$ or the $\mathrm{SW}$ dynamic pressure $P_{\mathrm{d}}$ at weak SW. Under its significant amplification during strong storms, the enhancement of $U_{\mathrm{PC}}$ slows down, becomes nonlinear, i.e. slower than the linear law. Then the enhancement almost stops, after reaching critical values of 1) interplanetary fields (electric $E_{\mathrm{SW}}$ and/or southward IMF component $B_{\mathrm{S}}$ ) [Siscoe et al,. 2002; Borovsky et al., 2009; Kan et al., 2010; Lyatsky et al., 2010; Wilder et al., 2011; Gao et al., 2013 and references therein), and 2) dynamic pressure $P_{\mathrm{d}}$, as shown in [Karavaev et al., 2012a, b; Mishin et al., 2015, 2016]. This phenomenon of slowdown in the enhancement of $U_{\mathrm{PC}}$ and $\Psi$ is termed the saturation of the polar cap potential [Siscoe et al., 2002] and its area [Merkin, Goodrich, 2007]. Here and elsewhere, the saturation of the polar cap magnetic flux is taken to mean the slowdown of its linear growth depending on SW parameters. Moreover, by the total saturation of $\Psi$ we mean the absence of its growth when SW rises. Mishin et al. [2015, 2016] have noted a possible relationship of this phenomenon with the finite compressibility of the magnetosphere, namely with the fact that its dayside boundary is rarely observed inside the geostationary orbit [Shue et al., 1997, 1998; Kuznetsov, Suvorova, 1998; Dmitriev et al., 2014]. Most authors consider the saturation phenomenon as the slowdown of momentum and energy transfer through the dayside magnetopause depending on interplanetary fields $E_{\mathrm{SW}}$ or $B_{\mathrm{z}}$. At the same time, some authors associate this phenomenon with the feedback effect of the ionosphere on the processes at the magnetopause. Thus Siscoe et al. [2002] attribute the saturation of the reconnection there to a decrease in the magnetic field owing to amplification of field-aligned currents in zone 1. Maltsev, Lyatsky [1975], Kivelson, Ridley [2008] and Lyatsky et al. [2010] consider the saturation of energy transfer through the magnetopause by MHD waves as a result of an increase in the ionosphere conductivity. Furthermore, the saturation can be associated with the ring current and magnetotail currents. Kalegaev et al. [2008] have found that during strong storms with Dst $>150 \mathrm{nT}$, the magnetotail current is saturated and the main contribution to Dst variation is made by the ring 
current. It is clear, on the other hand, that the ring current amplification during superstorms, along with an increase in its thermal pressure, can reduce the magnetic field inside the magnetosphere [Suvorova et al., 2003]. Both these effects being in disbalance can change the total pressure inside the magnetopause and affect its position [Dmitriev et al., 2011]. This feedback effect of the ring current on the position of the magnetopause and, accordingly, on $\Psi$ and $U_{\mathrm{PC}}$ requires a special investigation, which, however, beyond the purpose of this paper and can be the subject of our further work.

As a rule, the dependence of the $U_{\mathrm{PC}}$ and $\Psi$ saturation on $P_{\mathrm{d}}$ was not deliberately considered, but Siscoe et al. [2002] have suggested that the level of the $U_{\mathrm{PC}}$ saturation depends on the level of $P_{\mathrm{d}}$, without any restriction on the latter. Mishin et al. [2016] have shown that the saturation manifests itself simultaneously in the slowdown of changes of the $\Psi$ and $\mathbf{S}$ fluxes and in the magnetopause standoff distance, depending on the increase in both $B_{\mathrm{S}}$ and $P_{\mathrm{d}}$. The authors have assumed that both the saturation processes (polar cap area saturation and finite compressibility of the magnetosphere) are interrelated, i.e., the size of the polar cap depends on the size of the dayside magnetosphere and is limited by the internal structure of the geomagnetic field lines related to the Earth core. In contrast to this idea, Lavraud, Borovsky [ 2008] and Lopez et al. [2010] attribute the slowdown in the growth of $U_{\mathrm{PC}}$ and $\Psi$ to the processes in the outer magnetosphere - a decrease in the size (length $l$ ) of the reconnection area at the dayside magnetopause, provided that the Ampere force prevails over the thermal pressure gradient in the magnetosheath. This condition can hold at small values of the parameter $\beta<<$ 1 (the ratio of $P$ to $P_{\mathrm{mag}}$ ) in the magnetosheath and of the Alfvén Mach number $M_{A}=V_{\mathrm{CB}} / V_{A} \geq 1 V_{S W}$ (the ratio of the SW velocity to the Alfvén Mach number ), for example, during the passage of an interplanetary magnetic cloud. Such a situation occurred during the November 20, 2003 superstorm. However, we analyze the behavior of $\beta$ and $M_{\mathrm{A}}$ only for this superstorm - one of the three superstorms examined in [Mishin et al, 2016.]. It is therefore impossible using data on only one event to answer the question about the nature of the saturation - whether it is caused by the slowdown in the growth of the size of the reconnection area at the magnetopause or of the polar cap through the slowdown of the compression rate of the dayside magnetosphere (see [Mishin et al., 2016]). To answer this question, we use data on two other superstorms of September 24-25, 1998 and April 6-7, 2000. During the latter, $\beta=0.35 \div 1.8, M_{\mathrm{A}} \sim 5 \div 10$. With such large values of Mach numbers $(M>5)$ when $\beta \sim 1$, according to the assumptions made in [Lavraud, Borovsky, 2008; Lopez et al., 2010], the efficiency of dayside reconnection should not weaken and retard the increase in $U_{\mathrm{PC}}$ and $\Psi$, i.e. the $\Psi$ saturation should not occur.

The structure of the paper is as follows. Section 1 describes database and processing methods. Section 2 analyzes the behavior of SW and IMF parameters during the superstorms considered, shows features of the saturation of the polar cap magnetic flux $\Psi$ as a function of interplanetary electric and magnetic fields and SW parameters responsible for the $\Psi$ saturation. Section 3 discusses the findings.

\section{DATABASE AND PROCESSING METHODS}

We have used data on three superstorms of September 24-25, 1998, April 6-7, 2000, and November 20, 2003, which have been studied in [Russell et al., 2000; Huttunen et al., 2002; Alex et al., 2006] and then in a series of papers [Karavaev et al., 2012a, b; Mishin et al., 2015, 2016]. Satellite data on SW parameters have been taken from [http.gsfc.cdaw.gov].

Geomagnetic data from the ground-based magnetometer network $\geq 110$ in the Northern Hemisphere were processed by means of the original magnetogram inversion technique (MIT) [Mishin, 1990, 1991]. Figure 1 shows MIT maps of field-aligned current (FAC) density in the polar ionosphere for the April 6-7, 2000 storm. Thick solid lines indicate boundaries of FAC regions $\mathrm{R}_{1}, \mathrm{R}_{2}$, and $\mathrm{R} 0$ (the polar cap) in accordance with the classification [Iijima, Potemra, 1978]. From the FAC density maps we determine polar cap boundaries R0 every minute and calculate time series of the variable part of the polar cap magnetic flux $\Psi_{1}(t)=\Psi(t)-\Psi_{0}$ equal to the difference between the total flux through the polar cap and its value for the quiet interval before the storm $\Psi_{0}$, which for the three events ranged from 0.17 to $0.30 \mathrm{GWb}$.

\section{April 2000}

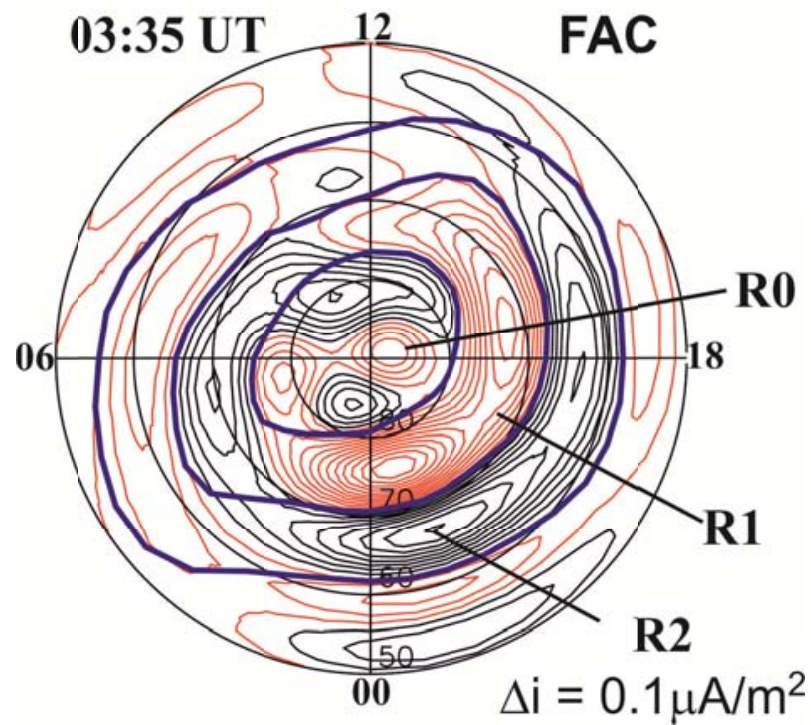

Figure 1. FAC maps in the northern high-latitude ionosphere in geomagnetic dipole coordinates (MLT geomagnetic latitude), obtained using MIT with $1 \mathrm{~min}$ resolution). Red (black) colors indicate downward (upward) currents. Blue solid lines depict boundaries between $\mathrm{R}_{1}, \mathrm{R}_{2}$, and R0 (the polar cap) 
In this case, the total magnetic flux $\Psi$ through the polar cap R0 is calculated as the surface integral $\Psi=\int B d S$,

Bd where $\mathbf{B}(r)$ is the dipole geomagnetic field, $S$ is the area of the spherical segment inside the boundary of the $\mathrm{R} 0$ zone at a height $r=115 \mathrm{~km}$. Besides, MIT computes the Poynting flux as a function of alternating magnetic flux $\varepsilon^{\prime} \sim \Psi_{1}^{2}$ through the polar cap area [Mishin et al., $2000,2011,2014]$. Note that we use the polar cap surface obtained by means of MIT, rather than the length of the reconnection region $l_{0}$ at the magnetopause, which is supposed but not measured by satellites, as is often done when calculating the Poynting flux $\varepsilon$ with the method described in [Perreault, Akasofu, 1978].

\section{VARIATIONS IN SW PARAMETERS AND SATURATION OF the POLAR CAP MAGNETIC FLUX}

\subsection{Variations in SW parameters}

Variations in SW parameters during the three superstorms are illustrated in Table 1 and Figures 2-4.

The Table shows the range of observed IMF components and SW parameters: velocity $V_{\mathrm{SW}}(\mathrm{km} / \mathrm{s})$, density $n\left(\mathrm{~cm}^{-3}\right)$, dynamic pressure $P_{\mathrm{d}}(\mathrm{nPa})$, merging electric field $E_{\mathrm{m}}$ [Kan, Lee, 1979], $A E$ index, and minimum value of the SYM- $H$ index (nT). Figures 2-4 show variations in the main SW parameters for each of the three storms. During sudden commencements (SC) of all the storms, SW parameters simultaneously sharply increase with the radial IMF component becoming more nonradial $\left(B_{x}>B_{y z}\right.$, Figure 3,c) and increasing the IMF modulus $\sqrt{B_{x}^{2}+B_{y}^{2}+B_{z}^{2}}$ and ultimately its magnetic pressure $P_{B} \propto B^{2}$ during the September 24-25, 1998 storm. After $\mathrm{SC}$, the SW velocity $V_{\mathrm{SW}}$ decreases very slowly (panel $a$ ). Panel $c$ shows variations in the nonradial IMF component $B_{y z}=\sqrt{B_{y}^{2}+B_{z}^{2}}$ and merging electric field penetrating into the magnetosphere:

$$
E_{m}=V_{\mathrm{SW}} B_{y z}\left(\sin \frac{\theta}{2}\right)^{2},
$$

where $\theta=\arctan \left(B_{y} / B_{z}\right)$ [Kan, Lee, 1979].

After SC of the November 20, 2003 superstorm, there was an SW compression region observed for several hours - an increase in density $\left(n>20 \mathrm{~cm}^{-3}\right)$, SW dynamic pressure $\left(P_{\mathrm{d}}>20 \mathrm{nPa}\right)$, and $\beta \sim 1-2$, with the southward IMF $\left(-10 \mathrm{nT}<B_{z}<-5 \mathrm{nT}\right)$. Then (after 10:30 UT), the SW compression region ended - there was a sharp drop in $n, P_{\mathrm{d}}$, and $\beta$. Against this background, IMF was northward for more than 1 hour, with an increase in its modulus up to $20 \mathrm{nT}$. Afterwards, a situation occurred which was typical for the passage of an interplanetary magnetic cloud - extremely strong southward IMF whose pressure was much higher than the thermal one $(\beta<0.1)$, despite the high average level of dynamic pressure $P_{\mathrm{d}} \sim 10 \mathrm{nPa}$ and its amplification 1.5 times.
20 November 2003
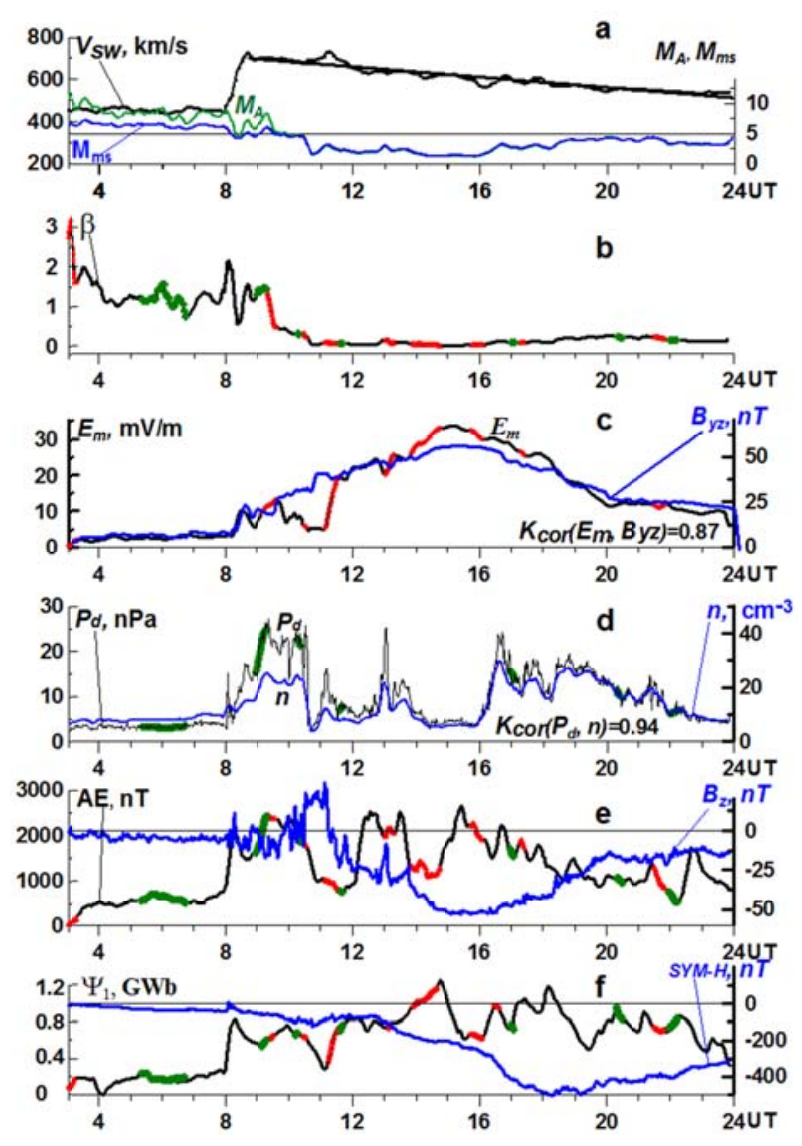

Figure 2. November 11, 2003 superstorm. Variations in SW parameters: velocity $V_{\mathrm{sw}}$ (bold line is the quasilinear approximation), Alfvén $M_{\mathrm{A}}$ and magnetosonic $M_{\mathrm{ms}}$ Mach numbers (green and blue lines) $(a)$; parameter $\beta(b)$; merging electric field $E_{\mathrm{m}}$ (black line, smoothed over 15-minute intervals), nonradial IMF $B_{y z}$ (blue line; at the bottom there is the correlation coefficient between $E_{\mathrm{m}}$ and $\left.B_{y z}\right)(c)$; SW dynamic pressure $P_{\mathrm{d}}$ (black line) and SW proton density $n$ (blue line, smoothed over 15-minute intervals; at the bottom there is the correlation coefficient between $P_{\mathrm{d}}$ and $\left.n\right)(d)$; $A E$ (black line, smoothed over 15-minute intervals) and IMF component $B_{\mathrm{z}}$ (blue line) (e); variable part of the polar cap magnetic flux $\Psi_{1}\left(\Psi_{0}=0.3 \mathrm{GWb}\right)(f)$. In black curves $b-f$, color marks UT intervals, selected when calculating the coefficients $d_{1}=\partial \Psi_{1} / \partial E_{\mathrm{m}}$ (red segments) and $d_{2}=\partial \Psi_{1} / \partial P_{d}$ (green segments)

Before the shock front of the September 24, 1998 storm and on it, there was an SW density increase with $\beta \geq 1$. After the passage of the shock front, there was a compression region with $\beta \sim 0.5 \div 1$. However, immediately after the front in the compression region, IMF $B_{z}$ was positive and turned to the south before the SW density decreased. Its values were not very large $\left(B_{\mathrm{S}} \sim 10 \mathrm{nT}\right)$, but the parameter $\mathbb{\beta}$ in $\mathrm{SW}$ was small, $<0.1$, and remained so even at a sudden jump in the SW dynamic pressure about $07 \mathrm{UT}$, when the Mach number increased to $M_{\mathrm{A}} \sim 7$. The turn of IMF to the north about 15:40 UT led to a drop in $A E$ activity. At the beginning of the third storm on April 6, 2000, after a jump in all SW parameters at the front, which caused the storm, there was no additional increase in dynamic pressure immediately after the passage of the front (observed 


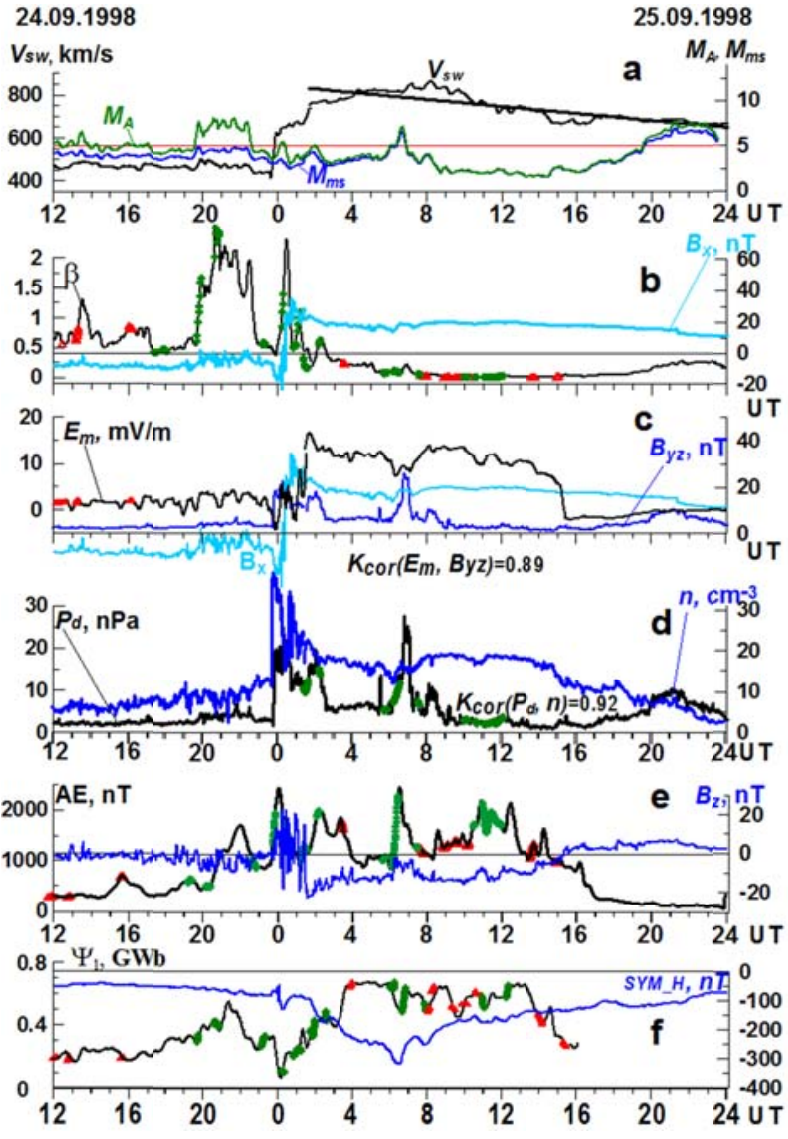

Figure 3. The same as in Figure 2 for the September 24 25,1998 superstorm. In addition, on panels $b$ and $c$, the blue color marks the behavior of $B_{x}$, which exceeded $B_{y z}$ after SC

during other storms), the dynamic pressure was high $(10-15 \mathrm{nPa})$, IMF $B_{z}$ was negative (around $-20 \mathrm{nT}$ ), and $\beta$ was finite $(\beta \sim 0.4)$.

In the middle of the main phase of the April 6, 2000 storm (about $24 \mathrm{UT}$ ), the IMF turned to the north and the $E_{\mathrm{m}}$ field fell. During the turn and shortly after, there occurred strong pulses of SW dynamic and thermal pressures with $\beta$ exceeding 1 .

The $A E$ index halved in value, but continued to be quite high $(A E \sim 500 \mathrm{nT})$ against the elevated pressure level $P_{\mathrm{d}} \sim 10 \mathrm{nPa}$.

Our correlation analysis shows that after SC in periods of high activity during all the storms the merging electric field $E_{\mathrm{m}}$ changed largely due to a change in the nonradial IMF component $B_{y z}$ with the correlation coefficient $K_{\text {cor }}\left(E_{\mathrm{m}}, B\right)=0.78 \div 0.87$, while
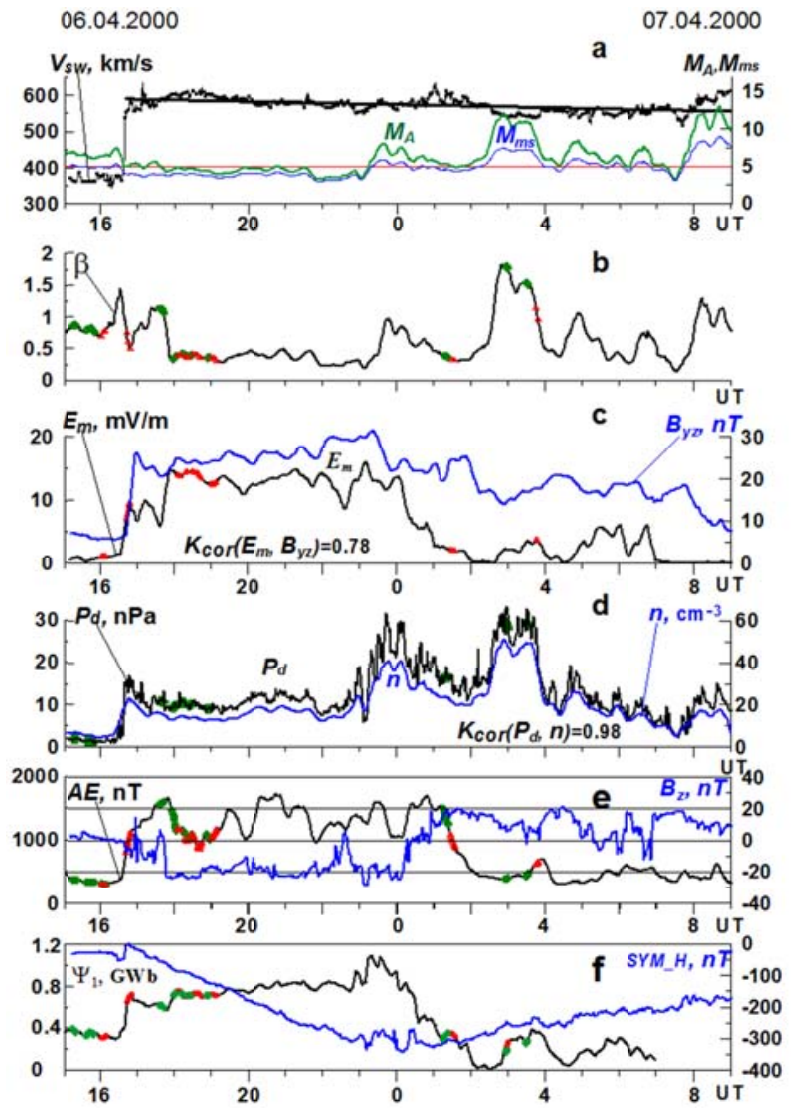

Figure 4. April 6-7, 2000 superstorm. Notations are the same as in Figure 2

$P_{\mathrm{d}}$ variations were mainly caused by variations in density $n$ with $K_{\text {cor }}\left(P_{\mathrm{d}}, n\right)=0.92 \div 0.98$. There was practically no correlation between $P_{\mathrm{d}}$ and $E_{\mathrm{m}}: K_{\text {cor }}\left(P_{\mathrm{d}}\right.$, $\left.E_{\mathrm{m}}\right) \leq 0.25$. An exception was the short interval 10:3111:15 UT immediately after the passage of the compression region behind the shock front of the 2003 storm when together with the IMF northward turn there were positive $P_{\mathrm{d}}$ and $E_{\mathrm{m}}$ pulses with $K_{\text {cor }}\left(P_{\mathrm{d}}, E_{\mathrm{m}}\right)=0.68$. Therefore, except for this interval, during all the three superstorms after SC, $E_{\mathrm{m}}$ and $P_{\mathrm{d}}$ can be taken as independent variables.

\subsection{Saturation of the polar cap magnetic} flux

As noted in Introduction, Mishin et al. [2016] have examined the behavior of the SW parameter $\beta=P / P_{B}(P$ and $P_{B}$ are $\mathrm{SW}$ thermal and magnetic pressures respectively) as well as Mach numbers: Alfvén $M_{\mathrm{A}}=V_{\mathrm{SW}} / V_{\mathrm{A}}$ and magnetosonic $M_{\mathrm{ms}}=V_{\mathrm{SW}} / V_{\mathrm{ms}}$,

Table 1

\begin{tabular}{|c|c|c|c|c|c|c|c|c|c|}
\hline $\begin{array}{c}\text { Parameters } \\
\text { Date }\end{array}$ & $B_{x}, \mathrm{nT}$ & $B_{y}, \mathrm{nT}$ & $B_{z}, \mathrm{nT}$ & $V_{N E}, \mathrm{~km} / \mathrm{s}$ & $n, \mathrm{~cm}^{-3}$ & $P_{\mathrm{d}}, \mathrm{nPa}$ & $E_{m}, \mathrm{mV} / \mathrm{m}$ & $A E, \mathrm{nT}$ & $S Y M-H, \mathrm{nT}$ \\
\hline Sep. 24-25, 1998 & $-23 \div 35$ & $-14 \div 39$ & $-23 \div 23$ & $650 \div 850$ & $1 \div 28$ & $0.5 \div 28$ & $0 \div 17$ & $73 \div 2865$ & $\leq-300$ \\
\hline April 06-07, 2000 & $-10 \div 23$ & $-30 \div 8$ & $-29 \div 21$ & $346 \div 636$ & $2.5 \div 57$ & $0.6 \div 31$ & $0.6 \div 16$ & $22 \div 2000$ & $\leq-300$ \\
\hline Nov. 20, 2003 & $-20 \div 19$ & $-26 \div 44$ & $-53 \div 30$ & $433 \div 754$ & $2.9 \div 33$ & $1.8 \div 27$ & $0.2 \div 34$ & $13 \div 3250$ & $\leq-450$ \\
\hline
\end{tabular}




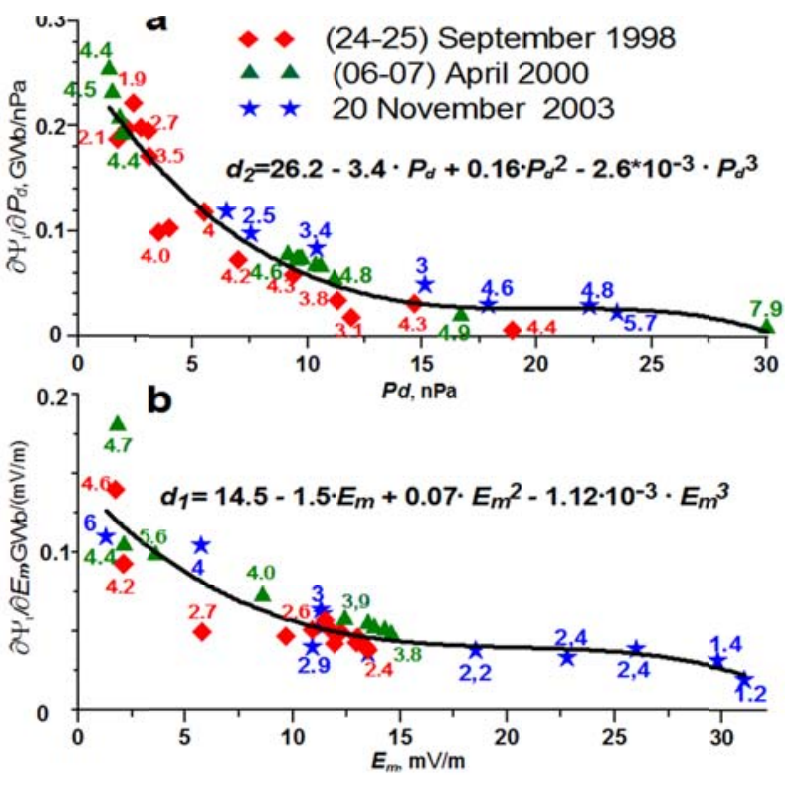

Figure 5. Derivatives $\partial \Psi_{1} / \partial P_{\mathrm{d}}(a)$ and $\partial \Psi_{1} / \partial E_{\mathrm{m}}(b)$ as functions of $P_{\mathrm{d}}$ and $E_{\mathrm{m}}$ during the three superstorms. Diamonds, triangles, and asterisks mark the intervals of the predominant change in $P_{\mathrm{d}}\left(\right.$ panel $a$ ) and $E_{\mathrm{m}}($ panel $b$ ), denoted in Figures 2-4. The numbers above and under them are the average values of the magnetosonic Mach number $M_{\mathrm{m}}$

where $V_{\mathrm{A}}$ and $V_{\mathrm{s}}$ are Alfvén and sound velocities, $V_{m s}=\sqrt{V_{A}^{2}+V_{s}^{2}}$ is the fast magnetosonic velocity. The authors have concluded that the saturation in the growth of the magnetic flux $\Psi$ and the Poynting flux $\varepsilon^{\prime}$ through the polar cap occurs at moderate values of the parameter $\beta<0.5$ and the Mach number $M_{\mathrm{ms}}<5$, which corresponds to the assumption [Lavraud, Borovsky, 2008; Lopez et al., 2010) that the saturation is associated with a decrease in the effective reconnection in the dayside magnetopause due to the slowdown in the growth of the length of the reconnection line under the Ampère force action (more precisely, Maxwellian tension). However, the behavior of the Mach numbers and the parameter $\beta$ was shown only for one event - the November 20, 2003 storm. Here, we carry out a detailed analysis of the behavior of all the SW parameters and polar cap magnetic flux $\Psi$ and check whether the saturation - the slowdown of $\Psi$ growth - occurred during the three superstorms under study, especially when Mach numbers were large and $\beta$ was finite, i.e., $\beta \leq 1$.

For this purpose, we explore two dependences of the polar cap magnetic flux derivatives $\Psi_{\mathrm{d}}\left(\partial \Psi_{1} / \partial P_{\mathrm{d}}\right.$ и $\left.\partial \Psi_{1} / \partial E_{\mathrm{m}}\right)$ on respective variables $P_{\mathrm{d}}$ and $E_{\mathrm{m}}$

Figure 5 shows dependences that are refined and augmented by data on the 1998 and 2000 storms, as compared to those we have obtained before (see Figure 4 in [Mishin et al., 2016]). The intervals of the predominant change in $P_{\mathrm{d}}$ or $E_{\mathrm{m}}$ are shown in Figures 2-4 respectively by green or red color. Mishin et al. [2016] adopted the criterion for selecting intervals according to which in each selected interval with a length from 10 to $40 \mathrm{~min}$, the observed monotonous variations in $\Psi_{1}$ with a range of much greater than the probable error in its measurement are caused by monotonous variations in one of the variables $E_{\mathrm{m}}$ or $P_{\mathrm{d}}$ against quasi-constancy of
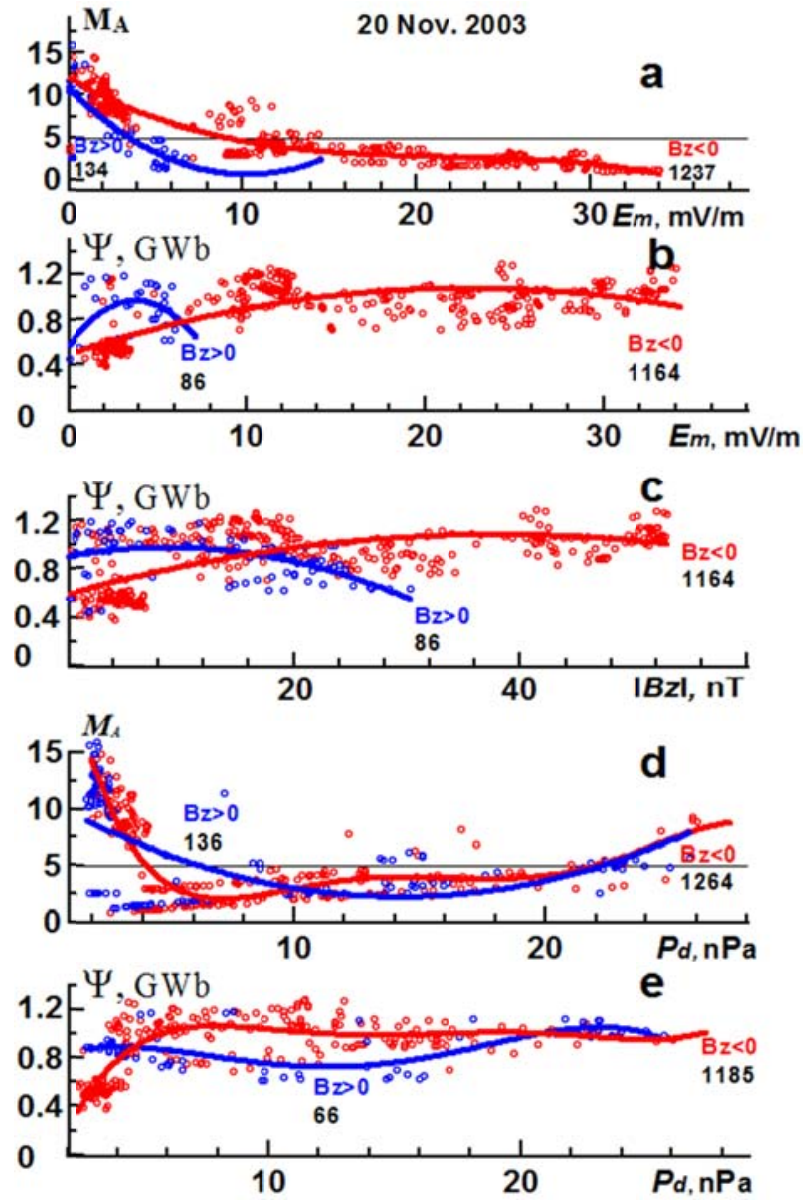

Figure 6. November 20, 2003 storm. Values of the Alfvén Mach number $M_{\mathrm{A}}$ and polar cap magnetic flux $\Psi(t)=\Psi_{1}(t)+\Psi_{0}$ as a function of $E_{\mathrm{m}}, B_{z}$, and $P_{\mathrm{d}}$ (circles) and their approximation by polynomials are indicated by solid lines in red for the southward direction of IMF; in blue, for the northward one. The numbers (black font) under $B_{z}>0$ and $B_{\mathrm{z}}<0$ show the number of points in samples. The prestorm value of $\Psi$ was $\Psi_{0}=0.3 \mathrm{GWb}$

the other. Further, using the maximum contribution method [Bazarzhapov et al., 1976; Mishin, 1990], in each selected interval, we compute the corresponding derivative $\partial \Psi_{1} / \partial P_{\mathrm{d}}$ or $\partial \Psi_{1} / \partial E_{\mathrm{m}}$

Figure 5 shows that the slowdown of variations in the functions $\Psi_{1}\left(P_{\mathrm{d}}\right)$ and $\Psi_{1}\left(E_{\mathrm{m}}\right)$, i.e. a decrease in the derivatives $\partial \Psi_{1} / \partial P_{\mathrm{d}}$ and $\partial \Psi_{1} / \partial E_{\mathrm{m}}$, occurs when $P_{\mathrm{d}}$ and $E_{\mathrm{m}}$ increase. We can assume that the right-hand side of these plots - the range of minimum values - corresponds to the saturation of the functions $\Psi_{1}\left(P_{\mathrm{d}}\right)$ and $\Psi_{1}\left(E_{\mathrm{m}}\right)$. The question arises about the degree of saturation in the range of small values of $P_{\mathrm{d}}$ and $E_{\mathrm{m}}$, when the derivatives can be large. To answer this question, we explore (Figures 6-8) the dependences of the Alfvén Mach number and $\Psi$ flux on $E_{\mathrm{m}}, B_{\mathrm{z}}$, and $P_{\mathrm{d}}$, obtained from the time series of the observed SW parameters $\left(E_{\mathrm{m}}, \boldsymbol{B}_{\mathrm{z}}\right.$, and $\left.P_{\mathrm{d}}\right)$ and polar cap magnetic flux by means of MIT. First note that almost all the periods in which $\partial \Psi_{1} / \partial P_{\mathrm{d}}$ и $\partial \Psi_{1} / \partial E_{\mathrm{m}}$ have the largest values (the leftmost part of the plots in Figure 5 $\left(\partial \Psi_{1} / \partial P_{\mathrm{d}}<3 \mathrm{nPa}, \partial \Psi_{1} / \partial E_{\mathrm{m}}<3.5 \mathrm{mV} / \mathrm{m}\right)$ with a large Mach number $M_{\mathrm{ms}} \sim 4-6$ correspond to the prestorm periods and do not affect the saturation during storms; therefore here we leave them out. 

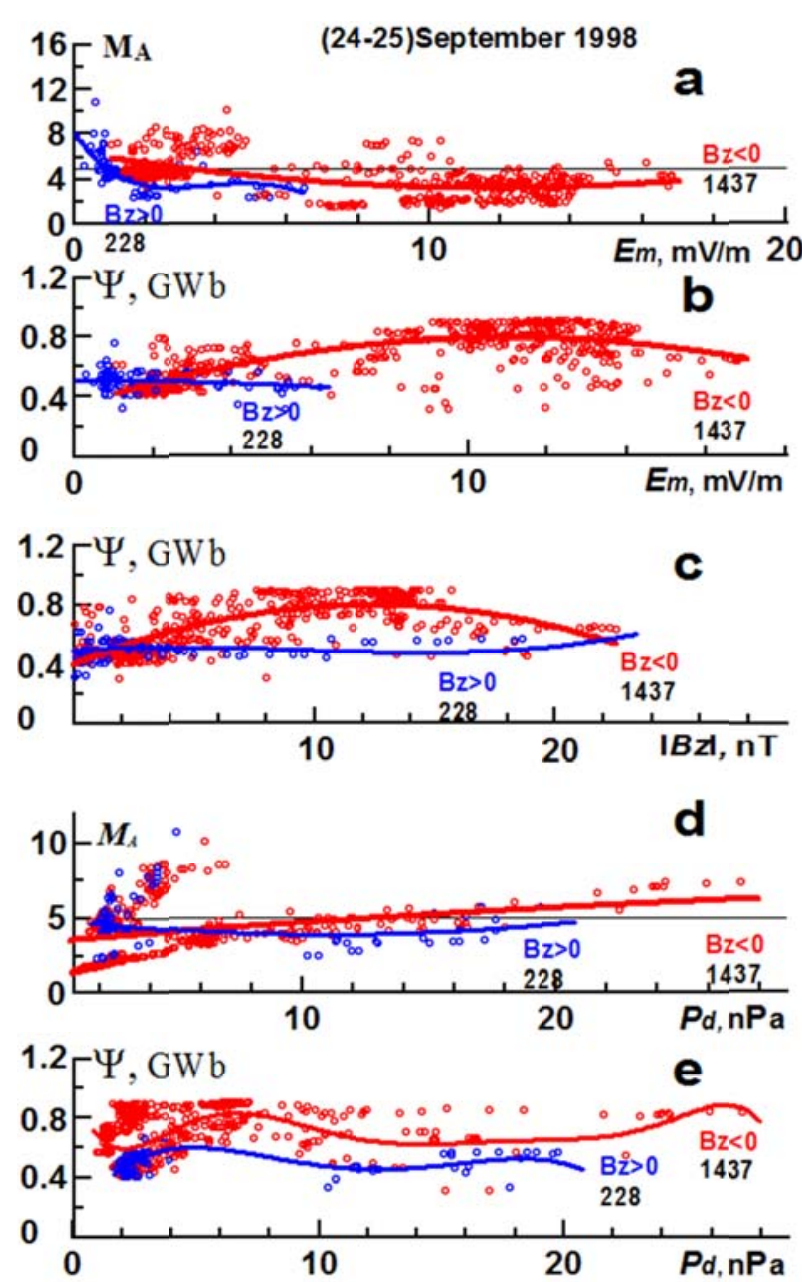

Figure 7. September 24-25, 1998 superstorm. Notations are the same as in Figure 6 for $\Psi_{0}=0.24 \mathrm{GWb}$

2.2.1. Saturation under increasing dynamic pressure

Immediately after the commencement of the November 20, 2003 storm, the pressure rise at the front (southward IMF) and rear (northward IMF) edges of the SW compression region (Figure 2, $d$ ) is accompanied by a monotonous decrease in $\partial \Psi_{1} / \partial P_{\mathrm{d}}$ (Figure 5,a). In this case, the large values $\beta \geq 1$ and $M_{\mathrm{A}} \geq 5$, produced by the pressure jump to $P_{\mathrm{d}}>26 \mathrm{nPa}$ between 09 and $10 \mathrm{UT}$, not only keep the $\Psi$ decrease monotonous amid $\beta=0.02 \div 0.3$, but also cause a decrease in $\partial \Psi_{1} / \partial P_{\mathrm{d}}$. The plot $\Psi\left(P_{\mathrm{d}}\right)$ (Figure $6, e$ ) shows a practically constant level of $\Psi$ with an increase in $P_{\mathrm{d}}$ from 4 to $\sim 25 \mathrm{nPa}$. During the 1998 storm (Figure 3), steep increases in $P_{\mathrm{d}}$ up to $>20 \mathrm{nPa}$, observed both in the $\mathrm{SW}$ compression region behind the shock front at $\beta \sim 1$ and at 06:07 UT on September 25, 1998 (when $\beta \leq 0.4, M_{A} \sim 7$ ) did not cause a steep increase in $\Psi$ and $\partial \Psi_{1} / \partial P_{\mathrm{d}}$ (Figures 5, 7).

It is important to note the presence of two saturation levels in all the events: higher under southward IMF and lower under northward IMF (Figures $6, f-8, f$ ). The greatest difference between them was observed during the April 06, 2000 storm, when strong pulses of $P_{\mathrm{d}}$ before and after the IMF turn to the north and the sharp drop in $\Psi$ occurred with steep increases in $\beta$ and Mach number. The short increases in $\Psi_{1}$ observed in this case (Figure 4) did not affect the saturation of $\Psi_{1}\left(P_{\mathrm{d}}\right)-$
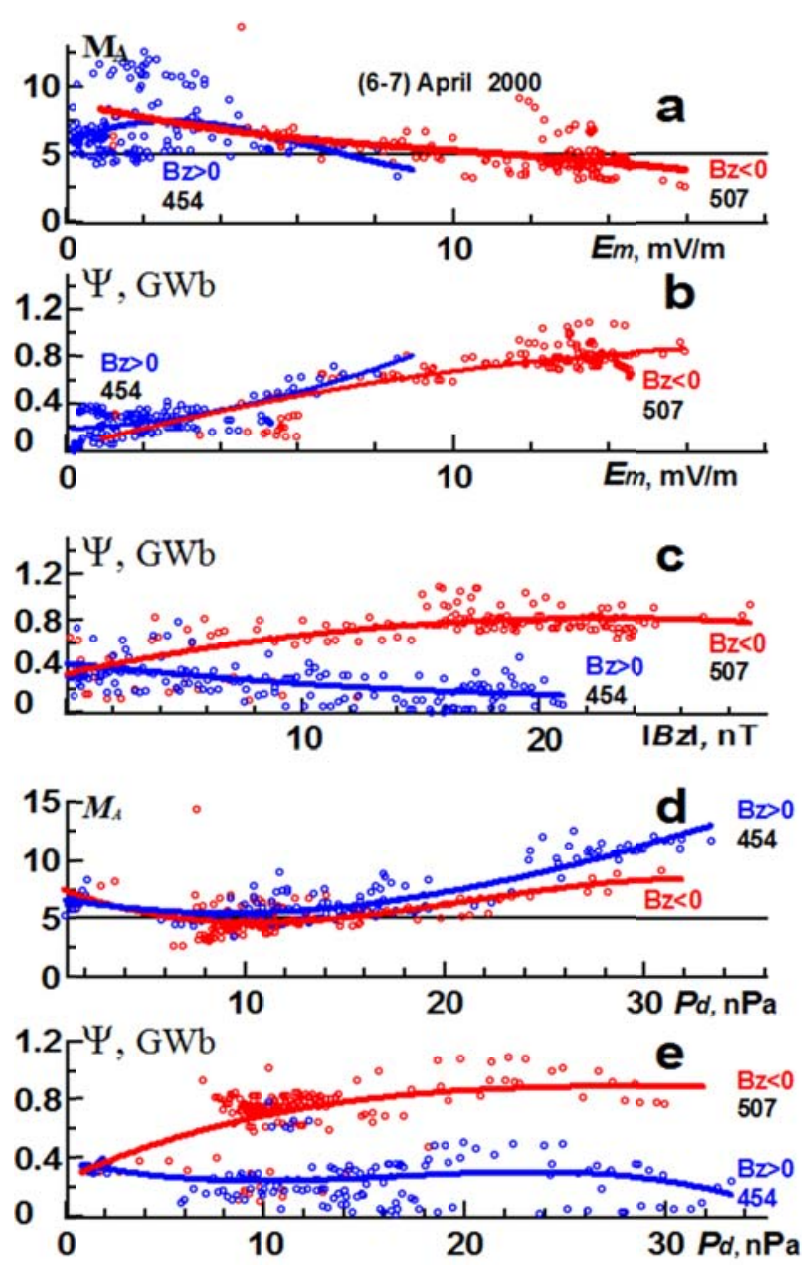

Figure 8. April 06-07, 2000 superstorm. Notations are the same as in Figure 6 for $\Psi_{0}=0.17 \mathrm{GWb}$

an increase in the levels of $\Psi$ for both signs of $B_{z}$ (Figure $8, f$ ) and deviations from the descending curve of $\partial \Psi_{1} / \partial P_{\mathrm{d}}\left(P_{\mathrm{d}}\right)$ (Figure 5, a). Thus, even during periods of a significant increase in Mach numbers and the parameter $\beta$, the saturation is not changed. Moreover, during the April 06-07, 2000 storm, the jump of $P_{\mathrm{d}}$ led not to an increase in the derivative $\partial \Psi_{1} / \partial P_{\mathrm{d}}$, i.e. to a breakdown of the saturation, but to its considerable decrease $\partial \Psi_{1} / \partial P_{\mathrm{d}} \rightarrow 0$, i.e. practically to the total saturation of $\Psi_{1}\left(P_{\mathrm{d}}\right)$. This is clearly seen in Figure 5. The point on the right edge of Figure 5, a, corresponds to the minimum value of $\partial \Psi_{1} / \partial P_{\mathrm{d}}<0.01$ if $M_{\mathrm{ms}}>7$, i.e. the greatest slowdown in the growth of $\Psi_{1}$. The adjacent points - blue asterisks with $M_{\mathrm{ms}}=4.6 \div 5.7-$ correspond also to the interval of compressed SW during the initial phase of the 2003 storm $(\beta \geq 1$ and $M_{\mathrm{A}} \geq 5$ ), described at the beginning of this Section. Thus, there is no doubt that the polar cap magnetic flux is saturated depending on the SW dynamic pressure not only at small values of Mach numbers and $\beta$ in SW, but also at their sharp increases during the $P_{\mathrm{d}}$ pulses observed in all the storms considered for both signs of IMF $B_{z}$.

2.2.2. Saturation with increasing southward IMF and merging electric field

Figures 6-8 show the $\Psi$ flux vs electric $E_{\mathrm{m}}$ and magnetic $B_{z}$ fields (panels $b, c$ ). On panels c, it is easy to 
see the presence of $\Psi$ saturation with respect to the growth in the $B_{z}$ modulus of IMF with its both signs: under northward IMF, the saturation occurs even at small values of $B_{\mathrm{z}} \geq 1 \div 3 \mathrm{nT}$, whereas under southward IMF $\left(B_{z}<0\right)$, at sufficiently large values of the modulus $B_{S}=\left|B_{z}\right|=10 \div 20 \mathrm{nT}$. Note also that the level of $\Psi$ under northward IMF is much lower than that under southward IMF (as has been shown in the previous Section). Thus, the saturation of the polar cap magnetic flux relative to the growth of the vertical IMF component occurs for all the three storms without any restrictions on values of Mach numbers and $\beta$.

A different situation arises, however, with the dependence $\Psi\left(E_{\mathrm{m}}\right)$. During the 2003 and 1998 storms, when the SW magnetic pressure dominated over the thermal pressure and Mach numbers were moderate $(M<5)$, the function $\Psi\left(E_{\mathrm{m}}\right)$ peaked in the middle of the range of observed values of $E_{\mathrm{m}}$ and then decreased with increasing $E_{\mathrm{m}}$ (Figures $6, b ; 7, b$ ). During the 2000 storm, when the SW thermal pressure was of order of the magnetic one and Mach numbers were large, $\Psi\left(E_{\mathrm{m}}\right)$ did not reach its maximum and the total saturation with respect to $E_{\mathrm{m}}$ did not occur. However, partial saturation, i.e. slowdown in the growth rate of $\Psi\left(E_{\mathrm{m}}\right)$, usually discussed by other authors (see Introduction) is shown in Figure 8, $b$ already for $E_{\mathrm{m}}=6 \mathrm{mV} / \mathrm{m}$ under southward IMF (red), and then this function becomes even flatter. If we additionally examine the behavior of the plot of $\partial \Psi_{1} / \partial E_{\mathrm{m}}$ versus $E_{\mathrm{m}}$ (Figure $5, b$ ), we can see that the last five points representing the 2000 storm (green triangles) lie at the very beginning of the gently sloping section of the approximating saturation curve, where $\partial \Psi_{1} / \partial E_{\mathrm{m}}$ is not below $0.05 \mathrm{GWb} /(\mathrm{mV} / \mathrm{m})$, unlike the two other storms.

Therefore, during the April 06-07, 2000 storm, we have a less effective slowdown in the growth of the function $\Psi=\Psi\left(E_{\mathrm{m}}\right)$ (Figure 8,d).

\section{DISCUSSION AND CONCLUSIONS}

The above results show some ambiguity in the behavior of the derivatives $\partial \Psi_{1} / \partial P_{\mathrm{d}}$ and $\partial \Psi_{1} / \partial E_{\mathrm{m}}$ during a sharp increase in $P_{\mathrm{d}}$ and $\beta$. Figures 6-8 clarify the saturation pattern. They show the behavior of Alfvén Mach number and $\Psi$ as a function of SW parameters $E_{\mathrm{m}}$, $B_{\mathrm{S}}$, and $P_{\mathrm{d}}$. The Figures indicate that in all the three superstorms the $\Psi$ saturation depends on the southward IMF component and the SW dynamic pressure. The $\Psi$ $\left(E_{\mathrm{m}}\right)$ curve reaches the saturation regime for the 1998 and 2003 superstorms, caused by the passage of magnetic clouds with large $E_{\mathrm{m}}(15-30 \mathrm{mV} / \mathrm{m})$. However, during the April 06, 2000 superstorm, the saturation of $\Psi\left(E_{\mathrm{m}}\right)$ was weak, most likely due to the IMF turn to the north, stop of the growth of $E_{\mathrm{m}}$ at $\sim 13 \mathrm{mV} / \mathrm{m}$, and completion of the active phase of the storm (see 2.2.2). Let us emphasize here that the $\Psi$ saturation relative to the growth of the southward IMF component $B_{\mathrm{S}}$ was achieved in this case. After reaching the maximum, the $\Psi\left(B_{\mathrm{S}}\right)$ curve dipped with further increasing $B_{\mathrm{S}}$ for all the events (red curves in Figures $6, c-8, c$ ). It is important to add here that the blue curves in the same Figures show that the $\Psi\left(B_{z}\right)$ saturation also occurs under northward IMF. At least, in all the events $\Psi$ does not grow with increasing northward IMF.

The obtained $\Psi\left(P_{\mathrm{d}}\right)$ saturation in all the events with both signs of $B_{z}$ and an increase in its level during the IMF turn from north to south (Figure 6, $f-8, f$ ) corresponds to the observed [Kovner, Feldstein, 1973; Shue et al., 1998; Dmitriev et al., 2014] additional compression of the magnetopause in such a turn and our assumption [Mishin et al., 2016] about its associated polar cap area growth The presence of the $\Psi\left(P_{\mathrm{d}}\right)$ saturation under northward IMF, when the effect of the dayside reconnection is minimal, is most pronounced during the 2000 storm with high $P_{\mathrm{d}}$ pulses observed after the IMF northward turn, and also immediately after SC during the passage of the SW compression region during the 2003 and 1998 storms. The intersection of the $\Psi$ saturation levels at different signs of $B_{z}$ (panels $c$ and $e$ in Figure 6) corresponds to the time span of the IMF northward turn upon the passage of the compression region after $\mathrm{SC}$, when $E_{\mathrm{m}}$ and $P_{\mathrm{d}}$ variations cannot be considered as independent (see Section 2.1). Of special note is the following fact: curves $d$ in Figures 6-8 show an increase in the Mach number up to $M_{\mathrm{A}} \sim 6-10$ during the 2000 event and up to $M_{\mathrm{A}} \sim 8$ during the 2003 storm for both signs of $B_{z}$ with the total saturation of $\Psi\left(P_{\mathrm{d}}\right)$, i.e., $\Psi$ does not grow at large values of $P_{\mathrm{d}}$ (curves $C$ ). The presence of saturation under northward IMF, although at a lower level of $\Psi$ than that under southward IMF, argues for our assumption that the expansion of the polar cap is inhibited by the increasing geomagnetic field pressure during magnetopause compression through connection of geomagnetic field lines with the Earth core, which reveals itself at higher latitudes and at a lower level of geomagnetic activity. This final, quite high saturation level of $\Psi\left(B_{z}>0\right)=0.30 \div 0.8 \mathrm{GWb}$ is explained by the fact that the positive IMF component $B_{z}$ increases the IMF modulus and the total external pressure $\hat{P}=P+P_{B}$ in the magnetosheath via the magnetic pressure $P_{B}$ and thereby enhances the compression of the magnetosphere and the expansion of the polar cap. When turning to the south, besides increasing the magnetic pressure outside the magnetopause, IMF has yet another effect by penetrating into the magnetosphere and reducing the geomagnetic field, thus causing an additional displacement of the magnetopause to Earth [Kovner, Feldstein, 1973] and an increase in the $\Psi$ saturation level.

Thus, during these superstorms there occurred the $\Psi$ saturation with an increase not only in the southward IMF component and merging electric field, but also in the northward IMF component, as well as in $P_{\mathrm{d}}$, followed by an increase in the Alfvén Mach number up to $M_{\mathrm{A}}=5 \div 10$. This contradicts the following assumptions: 1) about the unlimited growth of the transpolar potential with increasing $P_{\mathrm{d}}$ [Siscoe et al., 2002]; 2) that saturation can occur only relative to the growth of $E_{\mathrm{m}}$ and $B_{\mathrm{s}}$ during the passage of magnetic clouds and only at small Mach 
numbers [Lavraud, Borovsky, 2008; Lopez et al., 2010]. Therefore, the explanation that the saturation phenomenon is caused only by the weakening of the dayside reconnection efficiency [Lavraud, Borovsky, 2008; Lopez et al., 2010] is open to question. Our conclusions require further investigation using satellite and ground data, with detailed regression analysis and model experiments for superstorm conditions when both $P_{\mathrm{d}}$ and vertical IMF component (of both signs) reach quite high values and saturation conditions hold.

We are grateful to V.M. Mishin, S.B. Lunyushkin for their interest in our work and valuable comments, as well as to M.A. Kurikalova for carrying out calculations for the April 6, 2000 storm. This work was partially supported by RFBR grants Nos 15-05-05561, 17-5244001, and 18-55-53008. Solar wind parameters and geomagnetic indices $A E$ and $S Y M-H$ have been taken from the following websites: [http://cdaweb.gsfc. nasa.gov] and Kyoto WDC Website; geomagnetic data were obtained from the international projects CARISMA, INTERMAGNET, GIMA, MACCS, IMAGE, SuperDARN. We are thankful to heads of magnetic observatories O.A. Troshichev (AARI), E.P. Kharin (IDC B), B.M. Shevtsov, and A.V. Vinnitsky (IKIR FEB RAS), D.G. Baishev (IKFIA SB RAS), S. Khomutov (obs. Novosibirsk), O. Kusonsky (obs. Arti), Danish Meteorological Institute. Experimental data were also acquired with equipment of the Angara Multiaccess Center (ISTP SB RAS).

\section{REFERENCES}

Alex S., Mukherjee S., Lakhina G.S. Geomagnetic signatures during the intense geomagnetic storms of 29 October and 20 November 2003. J. Atmos. Sol. Terr. Phys. 2006, vol. 68, no. 7. pp. 769-780. DOI: 10.1016/j.jastp.2006.01.003.

Bazarshapov A.D., Mishin V.M., Shpynev G.B. A Mathematical Analysis of Geomagnetic Variation Fields. Gerlands Beitr. Geophysik. 1976, vol. 85, no. 1, pp. 76-82.

Borovsky J.E., Lavraud B., Kuznetsova M.M. Polar cap potential saturation, dayside reconnection, and changes to the magnetosphere. J. Geophys. Res. 2009, vol. 114, A03224. DOI: 10.1029/2009JA014058.

Dmitriev A., Suvorova A., Chao J.-K. A predictive model of geosynchronous magnetopause crossings. J. Geophys. Res. 2011, vol. 116, A05208. DOI: 10.1029/2010JA016208.

Dmitriev A.V., Suvorova A.V., Chao J.-K., Wang C.B., Rastaetter L., Panasyuk M.I., Lazutin L.L., Kovtyukh A.S., Veselovsky I.S., Myagkova I.N. Anomalous dynamics of the extremely compressed magnetosphere during 21 January 2005 magnetic storm. J. Geophys. Res. 2014, vol. 119, no. 2, pp. 877-896. DOI: 10.1002/2013JA019534.

Gao Y., Kivelson M.G., Walker R.J. Two models of cross polar cap potential saturation compared: Siscoe-Hill model versus Kivelson-Ridley model. J. Geophys. Res. Space Physics. 2013, vol. 118, no. 2, pp. 794-803.

Huttunen K.E.J., Koskinen H.E.J., Pulkkinen T.I., Pulkkinen A., Palmroth M., Reeves G.D., Singer H.J. April 2000 magnetic storm: Solar wind driver and magnetospheric response. J. Geophys. Res. 2002, vol. 107, no. A12, p. 1440.
Iijima T., Potemra T.A. Large-scale characteristics of field-aligned currents associated with substorms. J. Geophys. Res. 1978, vol. 83, no. A2, pp. 599-615.

Kalegaev V.V., Makarenkov E.V. Relative importance of ring and tail currents to Dst under extremely disturbed conditions. J. Atmos. Solar-Terr. Phys. 2008, vol. 70, p. 519.

Kan J., Lee L. Energy coupling function and solar wind magnetosphere dynamo. Geophys. Res. Lett. 1979, vol. 6, pp. $577-580$.

Kan J.R., Li H., Wang C., Tang B.B., Hu Y.Q. Saturation of polar cap potential: Nonlinearity in quasi-steady solar windmagnetosphere-ionosphere coupling. J. Geophys. Res. 2010, vol. 115, no. A8, pp. A08226. DOI: 10.1029/2009JA014389.

Karavaev Yu.A., Shapovalova A.A., Mishin V.M., Mishin V.V. The superstorm on 20.11.2003: Identification of the hidden dependencies of the tail lobe magnetic flux on the solar wind dynamic pressure. Proc. $9^{\text {th }}$ International Conference "Problems of Geocosmos", St. Petersburg, Petrodvorets, Russia, October. 2012a, pp. 245-250.

Karavaev Y.A., Shapovalova A.A., Mishin V.M., Mishin V.V. Super-storm 24-25.09.1998: identification of the hidden dependencies of the tail lobe magnetic flux on the solar wind dynamic pressure. Proc. $9^{\text {th }}$ International Conference "Problems of Geocosmos", St. Petersburg, Petrodvorets, Russia, October 2012b, pp. 251-255.

Kivelson M.G., Ridley A.J. Saturation of the polar cap potential: Inference from Alfven wing arguments. J. Geophys. Res. 2008, vol. 113, DOI: 10.1029/2007ja012302.

Kovner M.S., Feldstein Ya.I. On solar wind interaction with the Earth's magnetosphere. Planet. Space Sci. 1973, vol. 21, pp. 1191-1211.

Kuznetsov S.N., Suvorova A.V. Solar wind magnetic field and plasma during magnetopause crossings at geosynchronous orbit. Adv. Space Res. 1998, vol. 22, no. 1, pp. 63-66.

Lavraud B., Borovsky J.E. Altered solar windmagnetosphere interaction at low Mach numbers: Coronal mass ejections. J. Geophys. Res. 2008, vol. 113, A00B08. DOI: 10.1029/2008JA013192.

Lopez R.E., Bruntz R., Mitchell E.J., Wiltberger M., Lyon J.G., Merkin V.G. Role of magnetosheath force balance in regulating the dayside reconnection potential. $J$. Geophys. Res. 2010, vol. 115, A12216. DOI: 10.1029/2009JA014597.

Lyatsky W., Khazanov G.V., Slavin J.A. Saturation of the electric field transmitted to the magnetosphere. J. Geophys. Res. 2010, vol. 115, no. A8, pp. A08221. DOI: 10.1029/ 2009JA015091.

Maltsev Yu.P, Lyatsky W.B. Field-aligned currents and erosion of dayside magnetosphere. Planet. Space Sci. 1975, vol. 23, pp. 1257-1261

Merkin V.G., Goodrich C.C. Does the polar cap area saturate? Geophys. Res. Lett. 2007, vol. 34, no. 9, p. L09107.

Mishin V.M. The magnetogram inversion technique and some applications. Space Sci Rev. 1990, vol. 53, no. 1, pp. $83-163$.

Mishin V.M. The Magnetogram Inversion Technique Applications to the Problem of Magnetospheric Substorms. Space Sci Rev. 1991, vol. 57, no. 3-4. pp. 237-337.

Mishin V.M., Russell C.T., Saifudinova T.I., Bazarzhapov A.D. Study of weak substorms observed during December 8, 1990, Geospace Environment Modeling campaign: Timing of different types of substorms. J. Geophys. Res. 2000, vol. 105, no. A10, pp. 23263-23276. DOI: 10.1029/ 1999ja900495.

Mishin V.M., Förster M., Kurikalova M.A., Mishin V.V. 
The generator system of field-aligned currents during the April 06, 2000, superstorm. Adv. Space Res. 2011, vol. 48, no. 7 , pp. $1172-1183$.

Mishin V.V., Mishin V.M., Pu Z., Lunyushkin S.B., Sapronova L.A., Sukhbaatar U., Baishev D.G. Old tail lobes effect on the solar wind - magnetosphere energy transport for the 27 August 2001 substorm. Adv. Space Res. 2014, vol. 54, no. 12 , pp. 2540-2548. DOI: 10.1016/j.asr.2014.09.013.

Mishin V.V., Karavaev Y., Han J.P., Wang C. The saturation effect of the Poynting flux into the magnetosphere during superstorms: results of mit and the global PPMLRMHD model ... "Physics of Auroral Phenomena". Proc. XXXVIII Annual Seminar, Apatity. A.G. Yahnin. Apatity, Kola Science Centre, Russian Academy of Science. 2015, pp. 40-43.

Mishin V.V., Mishin V.M., Karavaev Yu.A., Han J.P., Wang C. Saturation of superstorms and finite compressibility of the magnetosphere: Results of the magnetogram inversion technique and global PPMLR-MHD model. Geophys. Res. Lett. 2016, vol. 43, no. 13, pp. 6734-6741. DOI: 10.1002/ 2016 GL069649.

Perreault P., Akasofu S.I. A study of geomagnetic storms. Geophys. J. R. Astr. Soc. 1978, vol. 54, no. 3, pp. 547-573. DOI: 10.1111/j.1365-246X.1978.tb05494.x.

Pulkkinen T.I., Dimmock A.P., Lakka A., Osmane A., Kilpua E., Myllys M., Tanskanen E.I., Viljanen A. Magnetosheath control of solar wind-magnetosphere coupling efficiency. J. Geophys. Res. Space Phys. 2016, vol. 121, pp. 8728-8739. DOI: 10.1002/2016JA023011.

Russell C.T., Wang Y.L., Raeder J., Tokar R.L., Smith C.W., Ogilvie K.W., Lazarus A.J., Lepping R.P., Szabo A., Kawano H., Mukai T., Savin S., Yermolaev Y.I., Zhou X.-Y., Tsurutani B.T.
The interplanetary shock of September 24, 1998: Arrival at Earth. J. Geophys. Res. 2000, vol. 105, no. A11, pp. 25143-25154. DOI: 10.1029/2000ja900070.

Shue J.H., Chao J.K., Fu H.C., Russell C.T., Song P., Khurana K. K., Singer H. A new functional form to study the control of the magnetopause size and shape. J. Geophys. Res. 1997, vol. 102, p. 9497.

Shue J.H., Song P., Russell C.T., Khurana K.K., Russell C.T., Singer H.J., Song P. Magnetopause location under extreme solar wind conditions. J. Geophys. Res. 1998, vol. 103, no. A8, pp. 17691-17700.

Siscoe G.L., Crooker N.U., Siebert K.D. Transpolar potential saturation: Roles of the region 1 current system and solar wind ram pressure. J. Geophys. Res. 2002, vol. 107, no. A10, p. 1321.

Suvorova A., Dmitriev A., Chao J.-K., Thomsen M., Yang Y.-H. Necessary conditions for geosynchronous magnetopause crossings. J. Geophys. Res. 2005, vol. 110, A01206. DOI: 10.1029/2003JA010079.

Wilder F.D., Clauer C.R., Baker J., Cousins E.P., Hairston M.R. The nonlinear response of the polar cap potential under southward IMF: A statistical view. J. Geophys. Res. 2011, vol. 116, no. A12, p. A12229.

URL: http.gsfc.cdaw.gov (accessed April 14, 2017).

\section{How to cite this article}

Mishin V.V., Karavaev Yu.A. Saturation of the magnetosphere during superstorms: new results from the magnetogram inversion technique. Solar-Terrestrial Physics. 2017. Vol. 3, iss. 3. P. 28-36. DOI: $10.12737 /$ stp-33201704 